\title{
Microencapsulação de probióticos por spray drying: avaliação da sobrevivência sob condições gastrointestinais simuladas e da viabilidade sob diferentes temperaturas de armazenamento
}

\author{
Microencapsulation of probiotics by spray drying: evaluation of survival in simulated \\ gastrointestinal conditions and availability under different storage temperatures

\begin{abstract}
Pablo Teixeira da Silva ${ }^{I^{*}}$ Leadir Lucy Martins Fries ${ }^{\mathrm{I}}$ Cristiano Ragagnin de Menezes ${ }^{\mathrm{I}}$ Cristiane de Bona da Silva ${ }^{I I}$ Hilda Hildebrand Soriani ${ }^{I I I}$ Juliana de Oliveira Bastos ${ }^{I}$ Mariana Heldt MottaII Roseane Fagundes Ribeiro ${ }^{\text {II }}$
\end{abstract}

\section{RESUMO}

\begin{abstract}
Oobjetivo deste trabalhofoi avaliar microcápsulas contendo Bifidobacterium animalis e Lactobacillus acidophilus, produzidas por spray drying. Ensaios de sobrevivência foram conduzidos para avaliar a resistência dos probióticos a condições gastrointestinais simuladas e a sua viabilidade durante 120 dias de armazenamento $a 4^{\circ} \mathrm{C}$ e $25^{\circ} \mathrm{C}$, além da análise morfológica das microcápsulas. A microencapsulação protegeu os probióticos das condições gastrointestinais simuladas, os quais permaneceram viáveis após 120 dias de armazenamento a $4^{\circ} \mathrm{C}$ e $25^{\circ} \mathrm{C}$, sendo mais viáveis a $4^{\circ} \mathrm{C}$. As microcápsulas apresentaram forma esférica, com superfície contínua relativamente lisa e sem fissuras. $O$ estudo indica que microcápsulas de $\boldsymbol{B}$. animalis e L. acidophilus, produzidas por spray drying, sobrevivem a condições gastrointestinais simuladas e podem ser melhor armazenadas por 120 dias $a 4^{\circ} \mathrm{C}$.
\end{abstract}

Palavras-chave: Bifidobacterium animalis, Lactobacillus acidophilus, microcápsulas.

\section{ABSTRACT}

The aim of this study was to evaluate microcapsules containing Lactobacillus acidophilus and Bifidobacterium animalis by spray drying. Survival assays were conducted to evaluate the resistance of probiotics to simulated gastrointestinal conditions and its availability during 120 days of storage at $4^{\circ} \mathrm{C}$ and $25^{\circ} \mathrm{C}$, besides morphological analysis of the microcapsules. Microencapsulation protected the probiotics from simulated gastrointestinal conditions, which also remained viable after 120 days of storage at $4^{\circ} \mathrm{C}$ and $25^{\circ} \mathrm{C}$, but more viable at $4^{\circ} \mathrm{C}$. The microcapsules showed spherical shape with relatively smooth continuous surface without cracks. The study indicates that microcapsules of
B. animalis or L. acidophilus by spray drying survive in simulated gastrointestinal conditions and can be better stored for 120 days at $4^{\circ} \mathrm{C}$.

Key words: Bifidobacterium animalis, Lactobacillus acidophilus, microcapsules.

\section{INTRODUÇÃO}

Os probióticos são definidos como microorganismos vivos capazes de melhorar o equilíbrio microbiano intestinal, produzindo efeitos benéficos à saúde do indivíduo (BRASIL, 2002), dentre os quais podemos destacar a prevenção de câncer de cólon; o aumento da resposta imune; o melhor trânsito intestinal; a redução de episódios de diarreia; a redução do colesterol sanguíneo e o alívio dos sintomas de intolerância à lactose (WEICHERT et al., 2012). Entretanto, para que os probióticos tenham sua ação eficaz, tem sido sugerido que os produtos devam conter pelo menos 6log UFC $\mathrm{g}^{-1}$ de micro-organismos vivos no momento do consumo (CHÁVEZ \& LEDEBOER, 2007), diferentemente do que diz BRASIL (2008), o qual estabelece o limite mínimo de $8 \log \mathrm{UFC} \mathrm{g}^{-1}$, com base na porção diária de alimento. Além disso, os probióticos devem sobreviver a um ambiente totalmente adverso, o trato gastrointestinal, tolerando ácidos, sais biliares e enzimas. Dessa forma, a microencapsulação tem sido estudada como

IDepartamento de Tecnologia e Ciência dos Alimentos, Universidade Federal de Santa Maria (UFSM), Avenida Roraima, nº 1000, 97105-900, Santa Maria, RS, Brasil. E-mail: pabloteixeiras@hotmail.com. *Autor para correspondência.

IIDepartamento de Farmácia Industrial, UFSM, Santa Maria, RS, Brasil.

IIIDepartamento de Biologia, UFSM, Santa Maria, RS, Brasil. 
uma alternativa para manter a viabilidade destes micro-organismos (YING et al., 2013).

A microencapsulação é uma técnica de encapsulação de substâncias ativas através de um agente encapsulante, o qual as protege do ambiente adverso, evitando o efeito de sua exposição inadequada. $\mathrm{O}$ agente encapsulante forma uma cápsula que se desfaz através de estímulo específico, liberando as substâncias ativas no local ideal (SOHAIL et al., 2011).

Alguns métodos têm sido usados para encapsulação de probióticos, dentre eles pode-se destacar o método por spray drying. Este método envolve a atomização de uma emulsão ou de uma suspensão de probióticos e agentes de encapsulação em uma câmara de secagem por ar quente, resultando na rápida evaporação de água. As vantagens do método por spray drying são a sua rapidez e custo relativamente baixo. A técnica é altamente reprodutível e sua característica mais importante consiste na sua adequação para aplicações industriais (BURGAIN et al., 2011).

O objetivo do presente trabalho foi encapsular B. animalis e $\boldsymbol{L}$. acidophilus por spray drying e avaliar a sobrevivência dos probióticos sob condições gastrointestinais simuladas e a viabilidade durante 120 dias de armazenamento a $4^{\circ} \mathrm{C}$ e $25^{\circ} \mathrm{C}$, além da análise morfológica das microcápsulas.

\section{MATERIAL E MÉTODOS}

Ativação e produção do concentrado de microorganismos probióticos

As culturas liofilizadas de $\boldsymbol{B}$. animalis (BB12) e L. acidophilus (LA05) (Christian Hansen) foram ativadas, em caldo MRS e leite em pó integral $10 \%$ esterilizado, respectivamente, ambas a $37^{\circ} \mathrm{C}$, por 24 horas. Os desenvolvimentos bacterianos foram submetidos à centrifugação a $4670 \mathrm{~g}$, a $4^{\circ} \mathrm{C}$ por 15 minutos e os precipitados foram lavados em solução salina $(0,85 \%)$ e centrifugados novamente por duas vezes (LISERRE et al., 2007).

Microencapsulação e contagem dos probióticos

Para a formulação do material de parede foram utilizados os seguintes agentes encapsulantes: acetato ftalato de celulose, glicerol, leite em pó integral, maltodextrina, trehalose, frutoligossacarídeo, hi-maize 260 e Tween 80. Os agentes encapsulantes foram dissolvidos em solução tampão fosfato salino $0,05 \mathrm{M}, \mathrm{pH} 7,6$, sob agitação. Ao final da dissolução, foi adicionado $1 \%$ dos probióticos ativados e centrifugados de
B. animalis e L. acidophilus, separadamente, obtendo duas formulações (FÁVARO-TRINDADE \& GROSSO, 2000).

Para a microencapsulação, foi utilizado um mini spray dryer LM, modelo MSD 1.0. As formulações probióticas secas foram coletadas do ciclone, colocadas em frascos de vidro hermeticamente fechados e armazenadas em dessecadores, contendo solução saturada $\mathrm{LiCl}$, dentro de uma incubadora $\left(25^{\circ} \mathrm{C}\right)$ e sob refrigeração $\left(4^{\circ} \mathrm{C}\right)$.

A viabilidade das culturas de $\boldsymbol{B}$. animalis e $\boldsymbol{L}$. acidophilus foi determinada pela contagem das microcápsulas. As microcápsulas foram desintegradas em solução tampão fosfato salino $0,05 \mathrm{M}, \mathrm{pH} 7,6$, na proporção de $0,01 \mathrm{~g} \cdot \mathrm{mL}^{-1}$. A solução tampão com as microcápsulas foram submetidas à agitação de $150 \mathrm{rpm}$, a $37^{\circ} \mathrm{C}$ por 5 minutos. Após a desintegração, os micro-organismos foram liberados e enumerados (GROSSO \& FÁVARO-TRINDADE, 2004). A enumeração foi realizada em ágar MRS pela técnica de semeadura em profundidade e incubação a $37^{\circ} \mathrm{C}$, em anaerobiose (Gaspak ${ }^{\mathrm{TM}}$ EZ Anaerobe, BD), por 72 horas (VINDEROLA \& REINHEIMER, 2000).

A avaliação da viabilidade dos probióticos durante $o$ armazenamento foi realizada para determinar o prazo de validade das microcápsulas obtidas. As contagens ocorreram após 1, 20, 40, 60, 80,100 e 120 dias de armazenamento a $4^{\circ} \mathrm{C}$ e $25^{\circ} \mathrm{C}$.

Sobrevivência dos probióticos às condições gastrointestinais simuladas

A sobrevivência das microcápsulas de $\boldsymbol{B}$. animalis e $\boldsymbol{L}$. acidophilus submetida às condições gastrointestinais simuladas foram avaliadas de acordo com método descrito por LISERRE et al. (2007), com modificações. Separadamente, alíquotas de $5 \mathrm{~g}$ de microcápsulas desidratadas de $\boldsymbol{B}$. animalis e $\boldsymbol{L}$. acidophilus foram adicionadas de $\mathrm{HCl} 1 \mathrm{M}$ até atingir pH de 1,4-1,9 e de soluções de pepsina (P7000, Sigma-Aldrich) e lipase (L3126, Sigma-Aldrich) até a obtenção de concentração de $3 \mathrm{~g} \cdot \mathrm{L}^{-1}$ e de $0,9 \mathrm{mg} \cdot \mathrm{L}^{-1}$, respectivamente. As amostras foram incubadas a $37^{\circ} \mathrm{C}$, sob agitação contínua, durante duas horas. $\mathrm{Na}$ etapa seguinte, o $\mathrm{pH}$ das amostras foi aumentado para 4,3-5,2, usando uma solução alcalina $(150 \mathrm{~mL}$ de $\mathrm{NaOH} 1 \mathrm{M}, 12,38 \mathrm{~g}$ de $\mathrm{NaH}_{2} \mathrm{PO}_{4} \cdot \mathrm{H}_{2} \mathrm{O}$ e água destilada até $1 \mathrm{~L})$. Bile (B8381, Sigma-Aldrich) e pancreatina (P3292, Sigma-Aldrich) foram adicionadas até a obtenção de uma concentração de $10 \mathrm{gL}^{-1}$ e de $1 \mathrm{gL}^{-1}$, respectivamente. As amostras foram incubadas novamente a $37^{\circ} \mathrm{C}$ por duas horas, sob agitação contínua. $\mathrm{Na}$ última etapa, o $\mathrm{pH}$ foi aumentado para 6,7-7,5, usando a mesma solução alcalina descrita 
acima. As concentrações de bile e pancreatina foram ajustadas para $10 \mathrm{~g} \cdot \mathrm{L}^{-1}$ e $1 \mathrm{~g} \cdot \mathrm{L}^{-1}$, respectivamente, e as amostras foram incubadas novamente a $37^{\circ} \mathrm{C}$ por duas horas sob agitação contínua, finalizando um total de 6 horas de análise. As contagens foram realizadas após 30 minutos, 2 horas, 4 horas e 6 horas de incubação.

Análise morfológica das microcápsulas

As amostras foram fixadas em suportes de alumínio, com auxílio de fita carbono dupla face e metalizadas em metalizador de fluxo iônico DENTON, modelo Desk II. A análise morfológica das microcápsulas foi obtida através de imagens de microscópio eletrônico de varredura JEOL, modelo JSM 6360.

Análise estatística

Os dados foram avaliados através de Análise de Variância (ANOVA), sendo que as médias foram comparadas pelo teste de Tukey, considerando o nível de significância de $5 \%(\mathrm{P}<0,05)$, utilizando o software SAS (Statistic Analysis System, versão 9).

\section{RESULTADOS E DISCUSSÃO}

Avaliação da viabilidade dos probióticos microencapsulados durante armazenamento

O dano celular e a perda de atividade podem ocorrer durante o processamento e/ou armazenamento dos micro-organismos. Portanto, a microencapsulação adequada assegura que os micro-organismos sobrevivam ao processamento e que permaneçam viáveis durante o armazenamento (OLIVEIRA et al., 2007).

De acordo com os resultados apresentados na tabela 1 , houve diferença significativa tanto para B. animalis quanto para $\boldsymbol{L}$. acidophilus armazenados a $4^{\circ} \mathrm{C}$ e $25^{\circ} \mathrm{C}$, durante os 120 dias de análises, verificando um decréscimo nas contagens com o passar dos dias. Isso pode ser explicado, pois os micro-organismos são metabolicamente ativos dentro das microcápsulas, produzindo ácidos metabólicos e bacteriocinas e/ou a perda de substratos (PEDROSO et al., 2012). Entretanto, ao final dos 120 dias, as contagens foram superiores a $6 \log \mathrm{UFC}_{\mathrm{g}}{ }^{-1}$, sendo este o mínimo aceitável para efeito probiótico em produtos (ROY, 2005), contrariamente ao que diz BRASIL (2008), o qual estabelece o limite mínimo de $8 \log$ UFC. $g^{-1}$ com base na porção diária de alimento. De acordo com RODRIGUES et al. (2011), a umidade relativa elevada, a alta temperatura e longos períodos de armazenamento são prejudiciais para a sobrevivência de probióticos.

Também pode ser verificado, na tabela 1 , que houve diferença significativa quando da comparação de $\boldsymbol{B}$. animalis e L. acidophilus, armazenados a $4^{\circ} \mathrm{C}$ com $25^{\circ} \mathrm{C}$. Resultados semelhantes foram encontrados por OKURO et al. (2013). Estes

Tabela 1 - Viabilidade das microcápsulas $\left(\log \mathrm{UFC}^{-1}\right)$ de $\boldsymbol{B}$. animalis e $\boldsymbol{L}$. acidophilus armazenadas durante 120 dias sob diferentes temperaturas.

\begin{tabular}{|c|c|c|c|}
\hline \multirow{2}{*}{ Micro-organismos } & \multirow{2}{*}{ Tempo (dias) } & \multicolumn{2}{|c|}{----Temperatura de armazenamento---------- } \\
\hline & & $4^{\circ} \mathrm{C}$ & $25^{\circ} \mathrm{C}$ \\
\hline \multirow{7}{*}{ B. animalis } & 1 & $11,87 \pm 0,06^{\mathrm{Aa}}$ & $11,87 \pm 0,06^{\mathrm{Aa}}$ \\
\hline & 20 & $10,92 \pm 0,08^{\mathrm{Ba}}$ & $10,68 \pm 0,07^{\mathrm{Bb}}$ \\
\hline & 40 & $10,04 \pm 0,15^{\mathrm{Ca}}$ & $9,61 \pm 0,11^{\mathrm{Cb}}$ \\
\hline & 60 & $9,24 \pm 0,09^{\mathrm{Da}}$ & $8,65 \pm 0,10^{\mathrm{Db}}$ \\
\hline & 80 & $8,50 \pm 0,12^{\mathrm{Ea}}$ & $7,78 \pm 0,15^{\mathrm{Eb}}$ \\
\hline & 100 & $7,82 \pm 0,07^{\mathrm{Fa}}$ & $7,00 \pm 0,12^{\mathrm{Fb}}$ \\
\hline & 120 & $7,20 \pm 0,09^{\mathrm{Ga}}$ & $6,30 \pm 0,11^{\mathrm{Gb}}$ \\
\hline \multirow{7}{*}{ L. acidophilus } & 1 & $11,52 \pm 0,09^{\mathrm{Aa}}$ & $11,52 \pm 0,09^{\mathrm{Aa}}$ \\
\hline & 20 & $10,60 \pm 0,11^{\mathrm{Ba}}$ & $10,37 \pm 0,06^{\mathrm{Bb}}$ \\
\hline & 40 & $9,75 \pm 0,08^{\mathrm{Ca}}$ & $9,33 \pm 0,10^{\mathrm{Cb}}$ \\
\hline & 60 & $8,97 \pm 0,11^{\mathrm{Da}}$ & $8,40 \pm 0,08^{\mathrm{Db}}$ \\
\hline & 80 & $8,25 \pm 0,09^{\mathrm{Ea}}$ & $7,56 \pm 0,11^{\mathrm{Eb}}$ \\
\hline & 100 & $7,59 \pm 0,10^{\mathrm{Fa}}$ & $6,80 \pm 0,13^{\mathrm{Fb}}$ \\
\hline & 120 & $7,04 \pm 0,08^{\mathrm{Ga}}$ & $6,12 \pm 0,10^{\mathrm{Gb}}$ \\
\hline
\end{tabular}

Médias seguidas pela mesma letra, maiúscula na coluna e minúscula na linha, não diferem estatisticamente entre si pelo teste de Tukey a 5\% de significância. 
resultados sugerem que a estabilidade dos probióticos microencapsulados aumenta com a diminuição da temperatura. Tal fenômeno ocorre pois os micro-organismos são mantidos num estado latente, evitando rearranjos no material de parede, impedindo, dessa forma, a exposição inadequada dos micro-organismos, promovendo um aumento da vida útil das microcápsulas (ALBERTINI et al., 2010). Temperaturas próximas a $0^{\circ} \mathrm{C}$ melhoram os índices de viabilidade celular, pois temperaturas mais baixas reduzem as taxas de reações químicas que são prejudiciais para os micro-organismos, tais como oxidação (NAG et al., 2011).

Sobrevivência dos probióticos às condições gastrointestinais simuladas

Um dos principais problemas dos probióticos é a baixa taxa de sobrevivência destes em $\mathrm{pH}$ gástrico e altas concentrações de sais biliares no intestino (SABIKHI et al., 2010), o que pode ser verificado na figura 1 , em que $\boldsymbol{B}$. animalis e L. acidophilus livres não resistiram às condições gastrointestinais simuladas, não havendo contagem de ambos após 120 e 240 minutos de incubação, respectivamente. PÁEZ et al. (2012) e RANADHEERA et al. (2012) obtiveram resultados semelhantes.

O mesmo resultado não foi verificado nos micro-organismos B. animalis e L. acidophilus encapsulados, figura 1, os quais, após 360 minutos de incubação, possuíam 9,86 e 9,03log $\mathrm{UFC} \cdot \mathrm{g}^{-1}$, respectivamente, demonstrando que a microencapsulação protege os micro-organismos das condições gastrointestinais simuladas. A baixa contagem após 30 minutos de incubação e crescimento posterior deve-se à utilização de acetato ftalato de celulose como material de parede, o qual é gastrorresistente, ou seja, somente dissolve-se em pH acima de 6,0, retardando a liberação dos microorganismos probióticos. A liberação será sempre no intestino e não no estômago, promovendo proteção aos micro-organismos probióticos durante o trânsito gastrointestinal (HEIDEBACH et al., 2012). Estudos de GEBARA et al. (2013), confirmam o aumento da resistência de probióticos microencapsulados quando expostos às condições gastrointestinais simuladas, comparando com a sobrevivência de células livres.

Análise morfológica das microcápsulas

As imagens capturadas através de microscopia eletrônica de varredura, figura 2, demonstraram a forma esférica das microcápsulas, com superfície contínua relativamente lisa, sem fissuras ou poros pronunciados, o que facilita o escoamento e a dispersão do material. Microcápsulas semelhantes foram encontradas por FÁVAROTRINDADE \& GROSSO (2002).

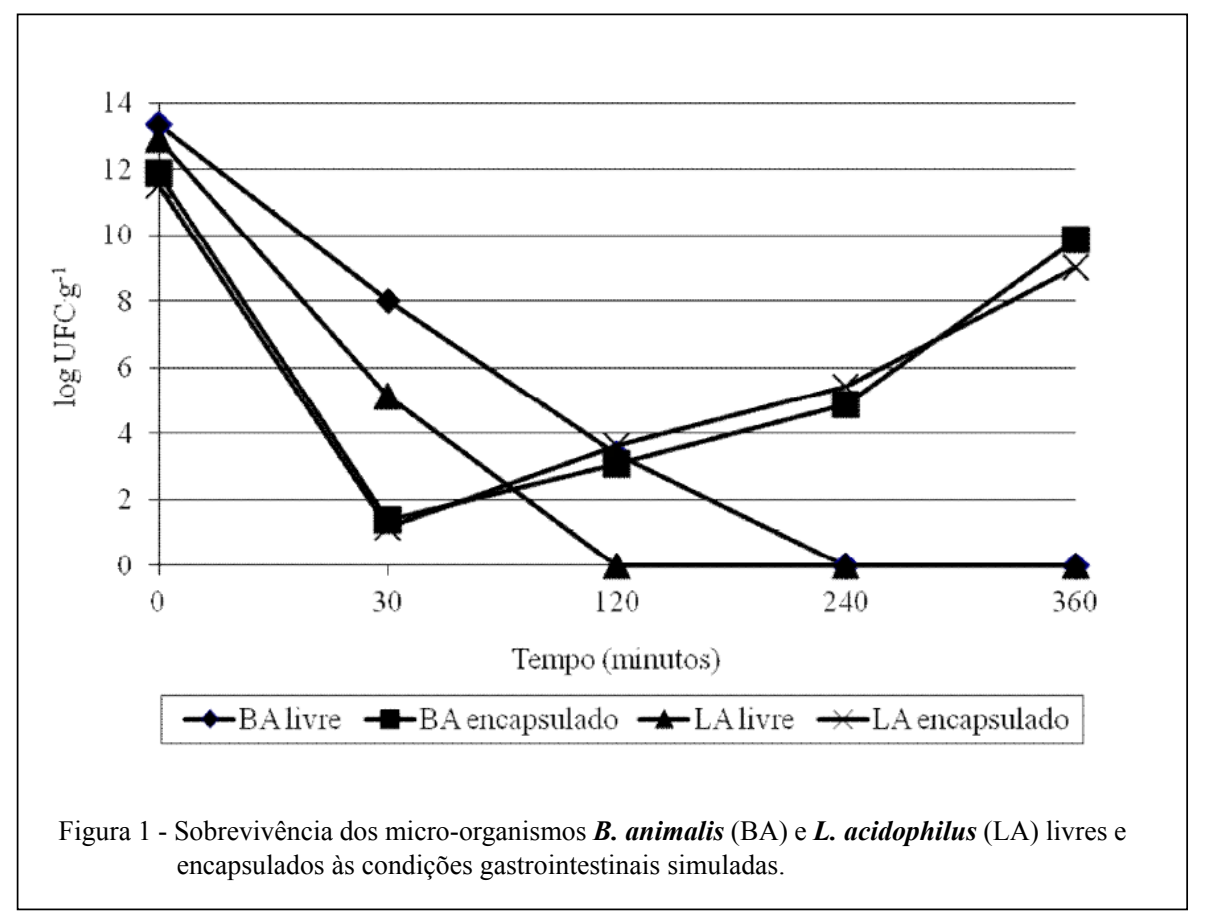

Ciência Rural, v.45, n.7, jul, 2015. 


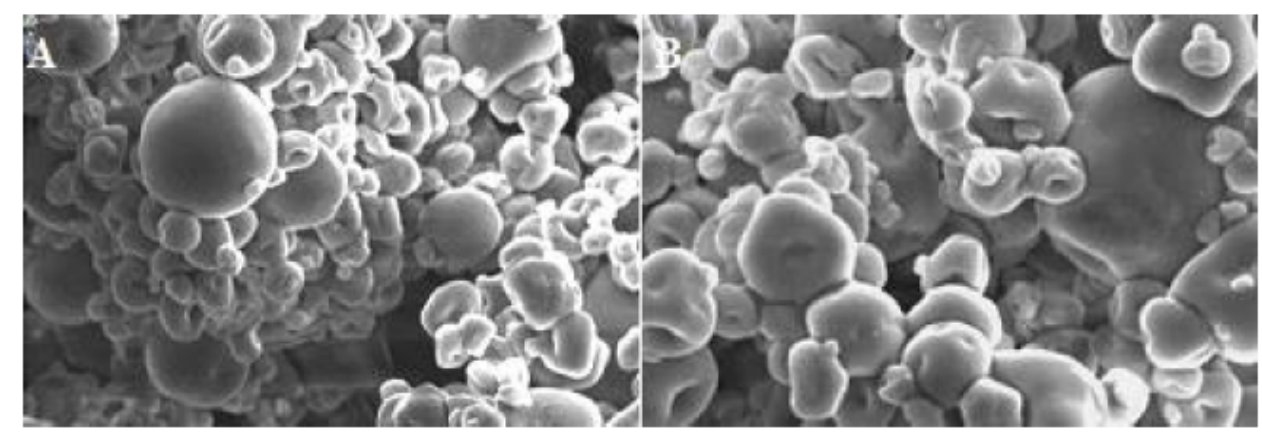

Figura 2 - Imagens do microscópio eletrônico de varredura para microcápsulas de $\boldsymbol{B}$. animalis (A, 2000x) e $\boldsymbol{L}$. acidophilus (B, 2000x).

\section{CONCLUSÃO}

O presente estudo mostrou que a microencapsulação de $\boldsymbol{B}$. animalis ou L. acidophilus por spray drying produziu microcápsulas esféricas e sem fissuras, que foram eficientes na proteção dos micro-organismos contra condições gastrointestinais simuladas. Além disso, podem ser armazenados, com melhores resultados, a $4^{\circ} \mathrm{C}$ por 120 dias.

\section{REFERÊNCIAS}

ALBERTINI, B. et al. Development of microparticulate systems for intestinal delivery of Lactobacillus acidophilus and Bifidobacterium lactis. European Journal of Pharmaceutical Sciences, v.40, n.4, p.359-366, 2010. Disponível em: <http:// www.sciencedirect.com/science/article/pii/S0928098710001569>. Acesso em: 28 jan. 2014. doi: 10.1016/j.ejps.2010.04.011.

BRASIL. Ministério da Saúde. Agência Nacional de Vigilância Sanitária. Resolução RDC n. 2, de 07 de janeiro de 2002. Aprova o Regulamento Técnico de Substâncias Bioativas e Probióticos Isolados com Alegação de Propriedades Funcional e ou de Saúde. Diário Oficial da União, Brasília, 09 de janeiro de 2002.

BRASIL. Ministério da Saúde. Agência Nacional de Vigilância Sanitária. Alimentos com alegações de propriedades funcionais e ou de saúde, novos alimentos/ingredientes, substâncias bioativas e probióticos: lista de alegações de propriedade funcional aprovadas. Disponível em: <http://www.anvisa.gov.br/alimentos/comissoes/ tecno lista alega.htm>. Acesso em: 07 jan. 2014.

BURGAIN, J. et al. Encapsulation of probiotic living cells: From laboratory scale to industrial applications. Journal of Food Engineering, v.104, n.4, p.467-483, 2011. Disponível em: $\quad<$ http://www.sciencedirect.com/science/article/pii/ S026087741000631X>. Acesso em: 06 jan. 2014. doi: 10.1016/j. jfoodeng.2010.12.031.

CHÁVEZ, B.E.; LEDEBOER, A.M. Drying of probiotics: optimization of formulation and process to enhance storage survival. Drying Technology, v.25, n.7-8, p.1193-1201,
2007. Disponível em: <http://www.tandfonline.com/doi/ full/10.1080/07373930701438576\#.UtUtYPRDvT8>. Acesso em: 07 jan. 2014. doi: 10.1080/07373930701438576.

FÁVARO-TRINDADE, C.S.; GROSSO, C.R.F. The effect of the immobilization of $\boldsymbol{L}$. acidophilus and B. lactis in alginate on their tolerance to gastrointestinal secretions. Milchwissenschaft, v.55, n.9, p.496-499, 2000. Disponível em: <http://www.cabdirect.org/ abstracts/20000406005.html>. Acesso em: 06 jan. 2014. ISSN: 0026-3788.

FÁVARO-TRINDADE, C.S.; GROSSO, C.R.F. Microencapsulation of $\boldsymbol{L}$. acidophilus $(\mathrm{La}-05)$ and $\boldsymbol{B}$. lactis $(\mathrm{Bb}-12)$ and evaluation of their survival at the $\mathrm{pH}$ values of the stomach and in bile. Journal of Microencapsulation, v.19, n.4, p.485-494, 2002. Disponível em: <http://www.ncbi.nlm. nih.gov/pubmed/12396385>. Acesso em: 28 jan. 2014. doi: 10.1080/02652040210140715.

GEBARA, C. et al. Viability of Lactobacillus acidophilus La5 in pectin-whey protein microparticles during exposure to simulated gastrointestinal conditions. Food Research International, v.51, n.2, p.872-878, 2013. Disponível em: <http://www.sciencedirect. com/science/article/pii/S0963996913001014>. Acesso em: 06 jan. 2014. doi: 10.1016/j.foodres.2013.02.008.

GROSSO, C.R.F.; FÁVARO-TRINDADE, C.S. Stability of free and immobilized Lactobacillus acidophilus and Bifidobacterium lactis in acidified milk and of immobilized $\boldsymbol{B}$. lactis in yoghurt. Brazilian Journal of Microbiology, v.35, n.1-2, p.151-156, 2004. Disponível em: <http://www.scielo. br/scielo.php?pid $=$ S1517-83822004000100025\&script $=$ sci arttext>. Acesso em: 06 jan. 2014. doi: 10.1590/S151783822004000100025 .

HEIDEBACH, T. et al. Microencapsulation of probiotic cells for food applications. Critical Reviews in Food Science and Nutrition, v.52, n.4, p.291-311, 2012. Disponível em: <http:// www.ncbi.nlm.nih.gov/pubmed/22332594>. Acesso em: 06 jan. 2014. doi: $10.1080 / 10408398.2010 .499801$.

LISERRE, A.M. et al. Microencapsulation of Bifidobacterium animalis subsp. lactis in modified alginate-chitosan beads and evaluation of survival in simulated gastrointestinal conditions. Food Biotechnology, v.21, n.1, p.1-16, 2007. Disponível em: <http:// 
www.tandfonline.com/doi/abs/10.1080/08905430701191064\#. UtZvRvRDvT8>. Acesso em: 06 jan. 2014. doi 10.1080/08905430701191064.

NAG, A. et al. Microencapsulation of probiotic bacteria using $\mathrm{pH}$-induced gelation of sodium caseinate and gellan gum. International Dairy Journal, v.21, n.4, p.247-253, 2011. Disponível em: <http://www.sciencedirect.com/science/article/pii/ S0958694610002505>. Acesso em: 06 jan. 2014. doi: 10.1016/j. idairyj.2010.11.002.

OKURO, P.K. et al. Co-encapsulation of Lactobacillus acidophilus with inulin or polydextrose in solid lipid microparticles provides protection and improves stability. Food Research International, v.53, n.1, p.96-103, 2013. Disponível em: $<$ http:// www.sciencedirect.com/science/article/pii/S0963996913002172>. Acesso em: 27 jan. 2014. doi: 10.1016/J.FOODRES.2013.03.042.

OLIVEIRA, A.C. et al. Microencapsulation of B. lactis (BI 01) and $\boldsymbol{L}$. acidophilus (LAC 4) by complex coacervation followed by spouted-bed drying. Drying Technology, v.25, n.10, p.16871693, 2007. Disponível em: <http://www.tandfonline.com/doi/ abs/10.1080/07373930701590939\#.UuaCaxBTvDc>. Acesso em: 27 jan. 2014. doi: 10.1080/07373930701590939.

PÁEZ, R. et al. Effect of heat treatment and spray drying on lactobacilli viability and resistance to simulated gastrointestinal digestion. Food Research International, v.48, n.2, p.748-754 2012. Disponível em: <http://www.sciencedirect.com/science/ article/pii/S0963996912002104>. Acesso em: 28 jan. 2014. doi: 10.1016/j.foodres.2012.06.018.

PEDROSO, D.L. et al. Protection of Bifidobacterium lactis and Lactobacillus acidophilus by microencapsulation using spraychilling. International Dairy Journal, v.26, n.2, p.127-132, 2012. Disponível em: <http://www.sciencedirect.com/science/ article/pii/S0958694612001021>. Acesso em: 27 jan. 2014. doi: 10.1016/j.idairyj.2012.04.008.

RANADHEERA, C.S. et al. In vitro analysis of gastrointestinal tolerance and intestinal cell adhesion of probiotics in goat's milk ice cream and yogurt. Food Research International, v.49, n.2, p.619-625, 2012. Disponível em: <http://www.sciencedirect.com/ science/article/pii/S0963996912003663>. Acesso em: 27 jan. 2014. doi: 10.1016/j.foodres.2012.09.007.

RODRIGUES, D. et al. Influence of L-cysteine, oxygen and relative humidity upon survival throughout storage of probiotic bacteria in whey protein-based microcapsules. International Dairy Journal, v.21, n.11, p.869-876, 2011. Disponível em: $<$ http://www.sciencedirect.com/science/article/pii/ S095869461100152X>. Acesso em: 06 jan. 2014. doi: 10.1016/j. idairyj.2011.05.005.

ROY, D. Technological aspects related to the use of bifidobacteria in dairy products. Lait, v.85, n.1-2, p.39-56, 2005. Disponível em: <http://hal.archives-ouvertes.fr/docs/00/89/55/93/PDF/ hal-00895593.pdf>. Acesso em: 07 jan. 2014. doi: 10.1051/ lait:2004026.

SABIKHI, L. et al. Resistance of microencapsulated Lactobacillus acidophilus LA1 to processing treatments and simulated gut conditions. Food and Bioprocess Technology, v.3, n.4, p.586593, 2010. Disponível em: <http://link.springer.com/article/10 .1007\%2Fs11947-008-0135-1>. Acesso em: 27 jan. 2014. doi: $10.1007 / \mathrm{s} 11947-008-0135-1$.

SOHAIL, A. et al. Survivability of probiotics encapsulated in alginate gel microbeads using a novel impinging aerosols method. International Journal of Food Microbiology, v.145, n.1, p.162168, 2011. Disponível em: <http://www.sciencedirect.com/ science/article/pii/S0168160510006975>. Acesso em: 06 jan. 2014. doi: 10.1016/j.ijfoodmicro.2010.12.007.

VINDEROLA, C.G.; REINHEIMER, J.A. Enumeration of Lactobacillus casei in the presence of L. acidophilus, bifidobacteria and lactic starter bacteria in fermented dairy products. International Dairy Journal, v.10, n.4, p.271-275, 2000. Disponível em: <http://www.sciencedirect.com/science/ article/pii/S0958694600000455>. Acesso em: 06 jan. 2014. doi: 10.1016/S0958-6946(00)00045-5.

WEICHERT, S. et al. The role of prebiotics and probiotics in prevention and treatment of childhood infectious diseases. Pediatric Infectious Disease Journal, v.31, n.8, p.859862, 2012. Disponível em: <http://journals.lww.com/pidj/ Documents/Prebiotics and Probiotics\%20ESPID\%20 Aug\%2012.pdf>. Acesso em: 07 jan. 2014. doi: 10.1097/ INF.0b013e3182620e52.

YING, D. et al. Microencapsulated Lactobacillus rhamnosus GG in whey protein and resistant starch matrices: Probiotic survival in fruit juice. Journal of Functional Foods, v.5, n. 1, p.98-105, 2013. Disponível em: < http://www.sciencedirect.com/science/article/pii/ S1756464612001351>. Acesso em: 06 jan. 2014. doi: 10.1016/j. jff.2012.08.009. 